Sharif University of Technology
Scientia Iranica
Transactions E: Industrial Engineering
hCIENTIA

\title{
Bi-objective optimization of non-periodic preventive maintenance strategy by considering time value of money
}

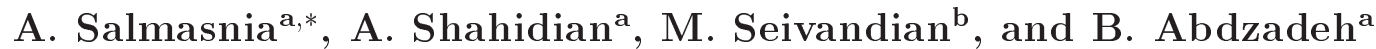 \\ a. Department of Industrial Engineering, Faculty of Engineering, University of Qom, Qom, Iran. \\ b. Department of Industrial Management, Faculty of Management, University of Tehran, Tehran, Iran. \\ Received 15 September 2018; received in revised form 26 January 2019; accepted 22 April 2019
}

\author{
KEYWORDS \\ Warranty; \\ Non-periodic \\ preventive \\ maintenance; \\ Time value of money; \\ Bi-objective \\ optimization.
}

\begin{abstract}
Recently, the design of Preventive Maintenance (PM) policies during the warranty period has attracted the attention of researchers. The methods mainly design warranty servicing strategies in a way to reduce the cost imposed on the manufacturer without considering the impact of customer dissatisfaction, while dissatisfaction with a product is an important issue, which may result in the loss of potential buyers and switching existing buyers to competitors. Therefore, in the present study, a bi-objective model was developed, which simultaneously minimized the manufacturer and buyer costs under a non-homogeneous Poisson process framework. Also, a non-periodic PM strategy was implemented in which PM actions were performed at discrete time instants in a way that the expected number of failures remained a constant value over all PM intervals. Furthermore, it is a known fact that the value of money is reduced over time due to different reasons, which has a significant impact on long-term contracts. Since PMs and repairs were conducted at different times, the time value of money was considered to estimate the cost more accurately. A comparative study was conducted to support the claim that the presented non-periodic reliability-based PM policy had better performance that a periodic PM policy.
\end{abstract}

(C) 2020 Sharif University of Technology. All rights reserved.

\section{Introduction}

All products and industrial systems eventually end in failure due to degradation, which can be fixed by corrective maintenance $[1,2]$. A warranty is a contractual agreement between the manufacturer and the buyer, which specifies the obligation of the manufacturer to

*. Corresponding author. Tel.: 02532103585

E-mail addresses: a.salmasnia@qom.ac.ir (A. Salmasnia);

shahidian.ali@gmail.com (A. Shahidian);

mesbah.sivandian@ut.ac.ir (M. Seivandian);

behnamabdzadeh@gmail.com (B.Abdzadeh)

doi: $10.24200 /$ sci. 2019.51791 .2365 undertake the servicing cost over the warranty period $[3,4]$. Warranty is a powerful tool to indicate product reliability and promotes the sale for the manufacturer as well. Hence, it can be a competitive advantage in marketing [5]. Moreover, it protects the buyer against early failure over the warranty period [6,7]. One of the effective methods to reduce the probability of failure during the warranty and post-warranty periods is performing Preventive Maintenance (PM), which controls the degradation process and becomes more important when the servicing cost is high [8]. Although performing PM leads to lower repair cost, it imposes extra cost on the system [9]. The cost of PM over the warranty period can be paid by either the manufacturer 
or the buyer. PM is valuable for the manufacturer when the reduction in the failure cost over the warranty period is greater than the extra cost of performing it [10].

In recent years, many researchers have focused on warranty and have proposed several models to investigate different aspects of this issue. Detailed studies on various warranty policies and their applications have been presented in $[5,11,12]$. There is a significant linkage between warranty and maintenance and many researchers utilized different maintenance policies to develop more efficient models. In this regard, Djamaludina et al. (2001) [13] developed a framework to study PM policies for products sold under warranty. Kim et al. (2004) [14] proposed a warranty model in which PM actions were carried out at discrete time instants over the warranty period. There are several studies that have been conducted in this context as classified in $[15,16]$.

Periodic and non-periodic maintenance policies are two common strategies in researches that consider warranty and maintenance, simultaneously. As a case in point, Wu et al. (2011) [17] proposed a model with a general periodic PM policy to minimize the cost imposed on the buyer by considering the calendar time of the first PM action and the degree of each PM action as decision variables. Park et al. (2017) [18] presented a periodic PM warranty model considering failure and repair time of the product. Su and Wang (2014) [19] proposed a non-renewing free repair warranty model for a second-hand product under a non-periodic age-dependent PM policy. Huang et al. (2017) [20] proposed a warranty model in which customers were classified into three categories according to their maintenance records and both periodic and non-periodic PM programs were considered.

In the existing approaches, the cost related to warranty and maintenance can be analyzed from the perspective of the buyer, manufacturer, or both. In this context, Park and Pham (2016) [21] developed a cost model by examining the renewable and nonrenewable warranty policies with block replacement and age replacement maintenance policies from the perspective of the buyer. Wang and Su (2016) [10] constructed a twodimensional PM policy for items sold under warranty from the manufacturer's perspective. Bouguerra et al. (2012) [22] presented a warranty model with a periodic PM policy to minimize the costs imposed on the buyer and manufacturer, simultaneously. Salmasnia and Yazdekhasti (2017) [23] developed an approach based on goal programming and desirability function to optimize the cost of the manufacturer and satisfaction level of the buyer, simultaneously.

Although many studies have been conducted to estimate the warranty and maintenance costs, the majority of them ignore the fact that the costs are imposed at different times. As a result, a factor that is of utmost importance in more realistic cost estimation in long term is the time value of money. Therefore, it is essential to include the Net Present Value (NPV) in analyzing the manufacturer and the buyer costs. In this regard, Teng (2006) [24] proposed a model through which the total cost of the manufacturer under an extended warranty was calculated by considering the time value of money.

Since the models in the related researches are very complicated, a few papers have concentrated on optimizing the costs of warranty and maintenance. In this regard, Fang and Huang (2010) [25] utilized a heuristic algorithm to develop a Bayesian decision model by which optimal strategy could be obtained under circumstances that the manufacturer did not have sufficient historical data. Shahanaghi et al. (2013) [26] presented a mathematical optimization model to achieve the optimal number and level of imperfect PM actions in which the occurrence of failure depended on both the age and usage of the product. Ambad and Kulkarni (2013) [27] used a genetic algorithm to minimize warranty cost with specific focus on warranty policies and reliability. Su and Wang (2016) [28] considered an availability-based warranty policy with an imperfect PM to optimize the PM schedule cycle by cycle. The characteristics of the existing researches in the literature are summarized in Table 1.

The aim of this study is to propose a non-periodic PM policy based on reliability in which PM actions are carried out in a way that the expected number of failures remains constant in PM intervals. As a result, the availability of the product will be the same at different time intervals. Also, the time value of money is taken into consideration to calculate the expected cost from the perspectives of both the buyer and the manufacturer. The manufacturer incurs the servicing and PM costs during the warranty period and the buyer incurs the costs related to the repairs and PM actions during the post-warranty period. This study presents a desirability function method for simultaneous minimization of the costs imposed on the buyer and the manufacturer. Finally, a Particle Swarm Optimization (PSO) algorithm is developed to find optimal values of PM level and PM intervals in a way that the minimum desirability of customer and manufacturer is maximized.

The rest of the paper is organized as follows: In Section 2, the problem will be presented in detail. The proposed model for achieving the optimal PM policy by considering the time value of money is given in Section 3. Section 4 illustrates the optimization approach used. Section 5 describes the solution approach. Section 6 consists of a numerical example, comparative study, and sensitivity analysis of the model parameters. Finally, in Section 7, conclusions and suggestions for future research are provided. 
Table 1. Summarized literature review.

\begin{tabular}{|c|c|c|c|c|c|c|}
\hline \multirow[b]{2}{*}{ Paper } & \multicolumn{2}{|c|}{ PM actions } & \multicolumn{2}{|c|}{ Viewpoint } & \multirow{2}{*}{$\begin{array}{l}\text { Multi-objective } \\
\text { function }\end{array}$} & \multirow{2}{*}{$\begin{array}{c}\text { NPV } \\
\text { consideration }\end{array}$} \\
\hline & Periodic & Non-periodic & Buyer & Manufacturer & & \\
\hline [13] & & $\sqrt{ }$ & $\sqrt{ }$ & $\sqrt{ }$ & & \\
\hline [14] & $\sqrt{ }$ & & $\sqrt{ }$ & $\sqrt{ }$ & & \\
\hline [17] & $\sqrt{ }$ & & $\sqrt{ }$ & & & \\
\hline [10] & $\sqrt{ }$ & & & $\sqrt{ }$ & & \\
\hline [19] & & $\sqrt{ }$ & & $\sqrt{ }$ & & \\
\hline [20] & $\sqrt{ }$ & $\sqrt{ }$ & & $\sqrt{ }$ & & \\
\hline [19] & & $\sqrt{ }$ & & $\sqrt{ }$ & & \\
\hline$[18]$ & $\sqrt{ }$ & & & $\sqrt{ }$ & & \\
\hline$[21]$ & $\sqrt{ }$ & & $\sqrt{ }$ & & & \\
\hline$[22]$ & $\sqrt{ }$ & & $\sqrt{ }$ & $\sqrt{ }$ & & \\
\hline$[24]$ & $\sqrt{ }$ & & & $\sqrt{ }$ & & $\sqrt{ }$ \\
\hline$[25]$ & & $\sqrt{ }$ & & $\sqrt{ }$ & & \\
\hline$[26]$ & $\sqrt{ }$ & & & $\sqrt{ }$ & & \\
\hline$[27]$ & & & & $\sqrt{ }$ & $\sqrt{ }$ & \\
\hline$[28]$ & & $\sqrt{ }$ & & $\sqrt{ }$ & & \\
\hline$[23]$ & $\sqrt{ }$ & & $\sqrt{ }$ & $\sqrt{ }$ & $\sqrt{ }$ & \\
\hline This paper & & $\sqrt{ }$ & $\sqrt{ }$ & $\sqrt{ }$ & $\sqrt{ }$ & $\sqrt{ }$ \\
\hline
\end{tabular}

\section{Problem definition}

A number of failures occur due to deterioration process within the life cycle and the rate of failures increases as the age of a product does. Performing PM actions can control degradation of the product, which leads to lower failure rate and less repair cost through warranty and post-warranty periods. There are two usual approaches to performing PM actions: (1) periodic and (2) non-periodic. Although periodic PM actions reduce the rate of failures at PM instants, the expected number of failures within distinct intervals is an increasing function of product age. Accordingly, the product in later PM intervals is less reliable, which is not suitable for the buyer and the manufacturer. This paper proposes a non-periodic PM policy in which PM actions are carried out so that the expected number of failures and consequently, product reliability at all intervals remain the same.

Most warranty contracts for sold products are longer than six months. Since the value of money decreases over time, taking the time value of money into account is of great significance. Although many studies have been conducted for analyzing the warranty cost, a few have taken into consideration the mentioned issue. To estimate the cost more accurately, this model uses NPV for considering the time value of money.

Warranty cost can be analyzed from the per- spective of the buyer, manufacturer, or both. Since both the manufacturer and the buyer tend to minimize their costs, it is more desirable to use a combined perspective. Some studies in the literature have used a combined perspective, but they have tried to achieve a win-win policy, which does not necessarily end in the optimal solution. To fill research gaps and obtain the optimal values of decision variables, this study presents a bi-objective mathematical programming to model the cost. Then, the presented bi-objective model is transformed into a single-objective one by employing the desirability function and max-min operator.

In this study, similarly to [14], the following three options are considered:

- Option 1: No PM actions are conducted over the life cycle;

- Option 2: PM actions are conducted over life cycle;

- Option 3: No PM actions are conducted over warranty period and discrete PM actions are conducted over post-warranty period.

Figure 1 shows that under every option, who will bear the costs of repairs and PM actions in the warranty and post-warranty periods.

The three options with a constant PM level of $m$ during the life cycle are graphically plotted in Figure 2. 


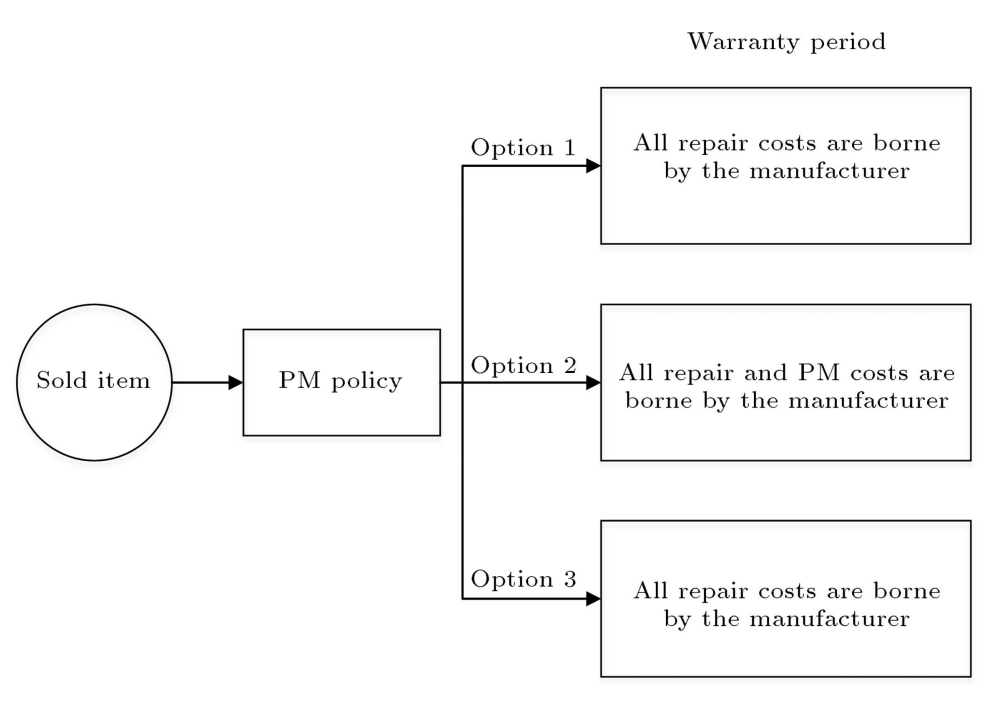

Post-warranty period

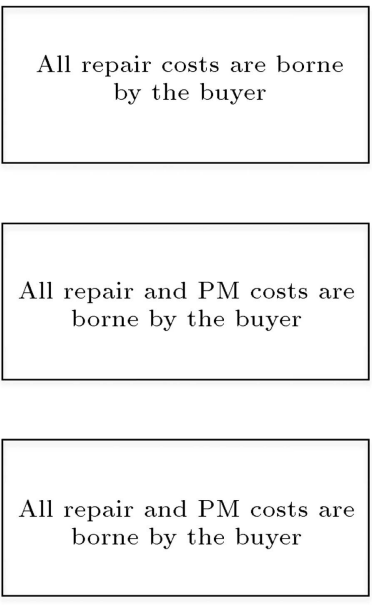

Figure 1. The cost structure of repairs and PM actions during warranty and post-warranty period.

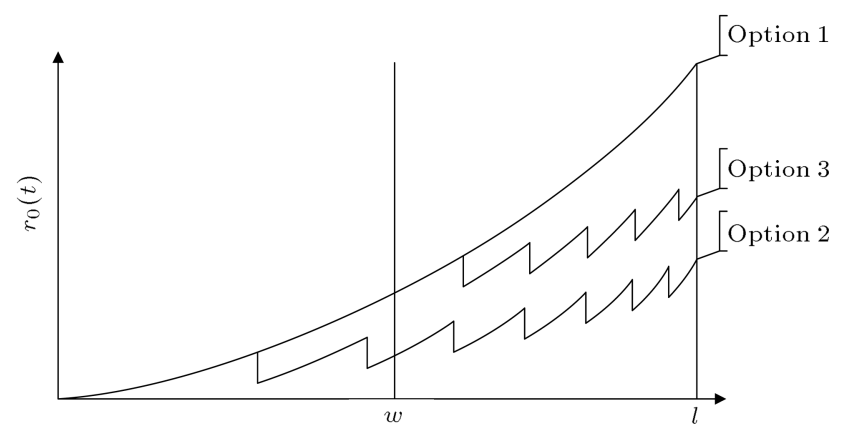

Figure 2. Graphical presentation of three Preventive Maintenance (PM) options [14].

As it is clear, the highest failure rate belongs to Option 1 , and Option 2 has the lowest failure rate.

\subsection{Notation}

The following notation in Table 2 is used to formulate the problem. It is divided into three parts: indices, decision variables, and parameters.

\subsection{Assumptions and definitions}

The presented model uses the following assumptions:

1. The product is repairable;

2. Maintenance and repair costs are borne by the manufacturer during the warranty period and by the buyer during the post-warranty period;

3. The failures are rectified through minimal repair. That is, the failure rate of the product after the repair is the same as that just before failure;

4. Time of repairs and PM actions, compared to the life of the product, is negligible;

5. The failure time of the product follows a Weibull distribution with a probability density function given by $f_{0}(t)=\lambda \beta(\lambda t)^{\beta-1} e^{-(\lambda t)^{\beta}}[29,30]$. Therefore, the failure rate function is modeled by a nonhomogeneous Poisson process given by:

$$
r_{0}(t)=f_{0}(t) /\left[1-F_{0}(t)\right]=\lambda \beta t^{\beta-1},
$$

with $B \geq 1 . r_{0}(t)$ being an increasing function of $t$.

6. The effect of PM action on the product age is modeled using the virtual age method, which was first proposed by Kijima (1989) [31] and afterwards, was modified by Kim et al. (2004) [14]. In this method, performing a PM action results in rejuvenation of the product. In other words, the virtual age of the product is reduced at the instant of performing the PM action. The amount of reduction depends on the maintenance level $(m)$, which is an integer, and $0 \leq m \leq M . m=0$ indicates that no $\mathrm{PM}$ action is performed and $M$ indicates the upper limit of the PM level. By assuming that the maintenance level is constant during the product lifetime, the virtual age after the $j$ th PM action is calculated by Eq. (2):

$$
\begin{aligned}
& v_{j}=v_{j-1}+\delta(m)\left(T_{P M_{j}}-T_{P M_{j-1}}\right), \\
& j=1,2, \ldots,
\end{aligned}
$$

where $T_{P M_{1}}$ is the time of the first PM action and a decision variable. $\delta(m)$ is the age reduction factor, which is a decreasing function of $M$ obtained as:

$$
\delta(m)=(1+m) e^{-m},
$$

with $\delta(0)=1$ and $\delta(M)=0$. It implies that as $m$ increases, the effect of aging is reduced. The virtual age at time $t$ can be computed as:

$$
\begin{aligned}
& v(t)=v_{j-1}+t-T_{P M_{j-1}}, \quad T_{P M_{j-1}} \leq t<T_{P M_{j}}, \\
& j=1,2, \ldots
\end{aligned}
$$


Table 2. Notations.

\begin{tabular}{ll}
\hline Indices: & \\
$i$ & Index of failures \\
$j$ & Index of PM actions \\
Decision variables: & \\
$m$ & PM level \\
$T_{P M_{1}}$ & Time to the first PM \\
Parameters: & \\
$C_{f}$ & Repair cost \\
$C_{f_{M}}\left(C_{f_{B}}\right)$ & Expected repair cost imposed on the manufacturer (buyer) \\
$C_{M}\left(C_{B}\right)$ & Total expected cost imposed on the manufacturer (buyer) \\
$C_{P M}\left(C_{P M}\right)$ & Expected PM cost imposed on the manufacturer (buyer) \\
$C_{P M, m}$ & PM cost with PM level $m$ \\
$f_{0}(t)$ & Failure density function with no PM \\
$F_{0}(t)$ & Failure distribution function with no PM \\
$l$ & Life cycle of the product \\
$M$ & Upper limit of PM level \\
$n_{f, l}$ & Expected number of failures over $[0, l)$ \\
$n_{f, w}$ & Expected number of failures over $[0, w)$ \\
$n_{P M, l}$ & Expected number of PM actions over $[0, l)$ \\
$n_{P M, w}$ & Expected number of PM actions over $[0, w)$ \\
$v(t)$ & Virtual age of the item at time $t$ \\
$W$ & Warranty period \\
$\delta(m)$ & Age reduction (rejuvenation) at maintenance level $m$ \\
\hline
\end{tabular}

According to Eqs. (2) and (4), the occurrence rate of failures can be obtained by Eq. (5):

$$
\begin{aligned}
& r[v(t)]=r\left(v_{j-1}+t-T_{P M_{j-1}}\right), \\
& T_{P M_{j-1}} \leq t<T_{P M_{j}}, \quad j=1,2, \ldots
\end{aligned}
$$

7. The expected number of failures between the $(j-$ 1 )th and $j$ th PM actions is equal to the expected number of failures from $t=0$ to the time of the first PM action, which can be formulated as:

$$
\begin{aligned}
& \int_{T_{P M_{j-1}}}^{T_{P M_{j}}} r_{0}\left(v_{j-1}+t-T_{P M_{j-1}}\right) d t \\
& \quad=\int_{0}^{T_{P M_{1}}} r_{0}(t) d t, \quad j=1,2, \ldots
\end{aligned}
$$

Therefore, $T_{P M_{j}}$, which is the upper limit of the integral in Eq. (6), can be obtained by:

$$
\begin{aligned}
& T_{P M_{j}}=\left(T_{P M_{1}}{ }^{\beta}+v_{j-1}{ }^{\beta}\right)^{\frac{1}{\beta}}-v_{j-1}+T_{P M_{j-1}}, \\
& j=1,2, \ldots
\end{aligned}
$$

Proof. The expected number of failures during $\left[T_{P M_{j-1}}, T_{P M_{j}}\right]$ is considered equal to that during $\left[0, T_{P M_{1}}\right]$. Therefore, $T_{P M_{j}}$ is derived as:

$$
\begin{aligned}
& \int_{T_{P M_{j-1}}}^{T_{P M_{j}}} r_{0}\left(v_{j-1}+t-T_{P M_{j-1}}\right) d t \\
& =\int_{0}^{T_{P M_{1}}} r_{0}(t) d t \Rightarrow \\
& \int_{T_{P M_{j-1}}}^{T_{P M_{j}}} \lambda \beta\left(v_{j-1}+t-T_{P M_{j-1}}\right)^{(\beta-1)} d t \\
& =\int_{0}^{T_{P M_{1}}} \lambda \beta(t)^{(\beta-1)} d t \Rightarrow \\
& \lambda\left[\left(v_{j-1}+t-T_{P M_{j-1}}\right)^{\beta}\right]_{T_{P M_{j-1}}}^{T_{P M_{j}}}=\lambda\left[t^{\beta}\right]_{0}^{T_{P M_{1}}} \Rightarrow \\
& \left(v_{j-1}+T_{P M_{j}}-T_{P M_{j-1}}\right)^{\beta}-v_{j-1}{ }^{\beta}=T_{P M_{1}}{ }^{\beta} \Rightarrow \\
& v_{j-1}+T_{P M_{j}}-T_{P M_{j-1}}=\left(T_{P M_{1}}^{\beta}+v_{j-1}{ }^{\beta}\right)^{\frac{1}{\beta}} \Rightarrow \\
& T_{P M_{j}}=\left(T_{P M_{1}}{ }^{\beta}+v_{j-1}{ }^{\beta}\right)^{\frac{1}{\beta}}-v_{j-1}+T_{P M_{j-1}} .
\end{aligned}
$$

8. $a_{i}$ denotes the expected occurrence time of the $i$ th failure within the time interval $\left[a, a_{i}\right]$, which is given by Eq. (8):

$$
a_{i}=\left(a^{\beta}+i \lambda^{-1}\right)^{\frac{1}{\beta}} .
$$


Proof. Eq. (8) is derived as:

$$
\begin{aligned}
& \int_{a}^{a_{i}} r_{0}(t) d t=i \Rightarrow \int_{a}^{a_{i}} \lambda \beta t^{\beta-1} d t=i \Rightarrow \\
& \lambda\left[t^{\beta}\right]_{a}^{a_{i}}=i \Rightarrow \lambda a_{i}^{\beta}-\lambda a^{\beta}=i \Rightarrow \\
& a_{i}^{\beta}=a^{\beta}+i \lambda^{-1} \Rightarrow a_{i}=\left(a^{\beta}+i \lambda^{-1}\right)^{\frac{1}{\beta}} .
\end{aligned}
$$

Therefore, the expected cost of the $i$ th failure using NPV can be expressed as:

$$
C_{i}^{N P V}=C_{f} e^{-\alpha a_{i}}
$$

where $\alpha$ denotes the discount rate and $C_{f}$ is the repair cost. Thus, the expected cost of failures during the life cycle of the product by considering the time value of money is formulated in Eq. (10):

$$
T C=\sum_{i=1}^{\left\lfloor n_{f, l}+0.5\right\rfloor} C_{i}^{N P V},
$$

where $n_{f, l}$ is the expected number of failures during the life cycle of the product and $T C$ is the total repair cost under consideration of the time value of money. $\lfloor x\rfloor$ denotes the greatest integer, which is less than or equal to $x$, and 0.5 is to modify/round off $n_{f, l}$.

\section{Model formulation}

This section describes the three PM options in detail and formulates the expected PM and repair costs imposed on the buyer and the manufacturer for each option by considering the time value of money and nonperiodic PM approach.

\subsection{Option 1}

In this option, no PM action is performed during the product life cycle. Therefore, only the cost of failures is imposed on the manufacturer and the buyer within the warranty and the post-warranty periods, respectively. Note that there is no optimization in this option and it is intended merely to assess the impact of PM on the costs to the buyer and the manufacturer.

\subsubsection{Manufacturer cost}

Let $n_{f, w}$ denote the expected number of failures during the warranty period, which can be calculated as:

$$
n_{f, w}=\int_{0}^{w} r_{0}(t) d t
$$

Therefore, the expected cost imposed on the manufacturer is given by:

$$
C_{M}=\sum_{i=1}^{\left\lfloor n_{f, w}+0.5\right\rfloor} C_{i}^{N P V}
$$

where $C_{i}^{N P V}$ is calculated by Eq. (9) and $a=0$.

\subsubsection{Buyer cost}

Let $n_{f, l}$ denote the expected number of failures during the product lifetime, which can be obtained as:

$$
n_{f, l}=\int_{0}^{l} r_{0}(t) d t .
$$

Therefore, the expected cost imposed on the buyer can be formulated as:

$$
C_{B}=\sum_{i=\left\lfloor n_{f, w}+0.5\right\rfloor+1}^{\left\lfloor n_{f, l}+0.5\right\rfloor} C_{i}^{N P V} .
$$

\subsection{Option 2}

In this option, PM actions are performed throughout the product lifetime and the first PM action is performed before the end of the warranty period. Therefore, the cost imposed on the buyer and the manufacturer consists of both repair and maintenance costs.

\subsubsection{Manufacturer cost}

Based on Eq. (6), the number of PM actions during the warranty period $n_{P M_{w}}$ is:

$$
n_{P M_{w}}=j_{\max _{w}}=\max \left[j \mid T_{P M_{1}} \leq w\right],
$$

where $j_{\max _{w}}$ is the index of the last PM action during the warranty period.

With respect to $n_{P M_{w}}$ the expected PM cost imposed on the manufacturer during the warranty period can be obtained as:

$$
C_{P M_{M}}=\sum_{j=1}^{n_{P M, w}} C_{j}^{N P V}
$$

where $C_{i}^{N P V}$ is calculated by Eq. (10).

By defining $N$ as the expected number of failures during the time interval $\left[0, T_{P M_{1}}\right]$ the number of the last PM actions before the $i$ th failure can be calculated by Eq. (18):

$$
\begin{aligned}
& N=\int_{0}^{T_{P M_{1}}} r_{0}(t) d t, \\
& j=\left\lfloor\frac{i}{N}\right\rfloor .
\end{aligned}
$$

Based on Eqs. (17) and (18), $T_{C M_{i}}$ during the warranty period should satisfy Eq. (19) sd shown in Box I, where $i_{\max }=\max \left[i \mid T_{C M_{i}} \leq w\right]$. This equation calculates the time of failure up to warranty expiration. The first part calculates the occurrence time of the failures until the first PM action. The second part calculates the occurrence time of failures from the first $\mathrm{PM}$ action up to the last one within the warranty period. The occurrence time of failures from the last 


$$
\begin{cases}\int_{0}^{T_{C M_{i}}} r_{0}(t) d t=i & t<T_{P M_{1}} \\ \int_{T_{P M_{j}}}^{T_{C M_{i}}} r_{0}\left(v_{j}+t-T_{P M_{j}}\right) d t=i-N \times j_{i} & T_{P M_{j}} \leq t<T_{P M_{j+1}}, \quad i=\left\lfloor N \times j_{i}\right\rfloor+1, \ldots,\left\lfloor N \times\left(j_{i}+1\right)\right\rfloor \\ \int_{T_{P M_{n}} T_{C M, w} r\left(v_{n_{P M, w}}+t-T_{P M_{n_{P M, w}}}\right) d t} & \\ \quad=i-N \times n_{P M, w} & T_{P M_{n_{P M}, w}} \leq t<w\end{cases}
$$

Box I

$$
\begin{cases}\int_{w}^{T_{C M_{i}}} r_{0}(t) d t=i & w \leq t<T_{P M_{n_{P M}, w}} \\ \int_{T_{P M_{j}}}^{T_{C M_{i}}} r_{0}\left(v_{j}+t-T_{P M_{j}}\right) d t=i-N \times j_{i} & T_{P M_{j}} \leq t<T_{P M_{j+1}}, \quad i=\left\lfloor N \times j_{i}\right\rfloor+1, \ldots,\left\lfloor N \times\left(j_{i}+1\right)\right\rfloor \\ \int_{T_{P M_{n}} T_{C M, l} r_{0}\left(v_{n_{P M, l}}+t-T_{P M_{n_{P M, l}}}\right) d t} & \\ \quad=i-N \times n_{P M, l} & T_{P M_{n_{P M}, l}} \leq t<l\end{cases}
$$

Box II

$\mathrm{PM}$ action up to the end of the warranty period is determined by the third section of Eq. (19).

With $n_{f, w}=i_{\max }$, the expected repair cost imposed on the manufacturer is calculated as follows:

$$
C_{f_{M}}=\sum_{i=1}^{n_{f, w}} C_{i}^{N P V}+C_{s_{M}},
$$

where $C_{s_{M}}$ is the expected failure cost during $\left[T_{C M_{n}, w}, w\right]$, which is calculated by Eq. (21):

$$
\begin{aligned}
C_{s_{M}} & =C_{f} \times \int_{T_{C M_{n} f, w}}^{w} r\left(v_{n_{P M, w}}+t-T_{P M_{n_{P M, w}}}\right) d t \\
& \times e^{-\alpha T_{s_{M}}}
\end{aligned}
$$

where $T_{s_{M}}$ is the time instant required to calculate NPV of the failure cost during $\left[T_{C M_{n_{f, w}}}, w\right]$. In this model, the mean of $T_{C M_{n f, w}}$ and $w$ is considered as $T_{s}$, which is calculated as follows:

$$
T_{s}=\frac{w+T_{C M_{n_{f, w}}}}{2} .
$$

Since the manufacturer cost consists of both the repair and the PM actions costs, during the warranty period, the cost imposed on the manufacturer can be obtained by Eq. (23):

$$
C_{M}=C_{f_{M}}+C_{P M_{M}}
$$

\subsubsection{Buyer cost}

Let $n_{P M_{l}}$ denote the number of PM actions during the product lifetime in Option 2, which is computed as follows:

$$
n_{P M_{l}}=j_{\max }=\max \left[j \mid T_{P M_{j}} \leq l\right],
$$

where $j_{\max }$ is the index of the last PM action during the product lifetime and $T_{P M_{j}}$ is obtained by Eq. (7). Then, the expected PM cost imposed on the buyer is given by Eq. (25):

$$
C_{P M_{B}}=\sum_{j=n_{P M, w}+1}^{n_{P M, l}} C_{j}^{N P V} .
$$

According to Eqs. (17) and (18), $T_{C M_{i}}$ during the post-warranty period must satisfy Eq. (26) as shown in Box II, where $i_{\max }=\max \left[i \mid w<T_{C M_{i}}<l\right]$.

By setting $n_{f, l}=i_{\text {max }}$, the expected repair cost imposed on the buyer is attained as follows:

$$
C_{f_{B}}=\sum_{i=n_{f, w}+1}^{n_{f, l}} C_{i}^{N P V}+C_{s_{B}},
$$

where $C_{s_{B}}$ is the expected failure cost during $\left[T_{C M_{n}, l}, l\right]$, which is obtained by Eq. (21).

Since the buyer cost includes the costs of PM actions and repairs during the post-warranty period, the expected total cost imposed on the buyer is computed through Eq. (28):

$$
C_{B}=C_{f_{B}}+C_{P M_{B}} \text {. }
$$




\subsection{Option 3}

Since performing PM actions begins after the warranty period in this option, the only cost imposed on the manufacturer is the cost of product failures during the warranty period. However, the cost imposed on the buyer includes both the failures and PM actions costs during the post-warranty period.

\subsubsection{Manufacturer cost}

After calculating the expected number of product failures in the warranty period $n_{f, w}$ by Eq. (11), the expected manufacturer cost in Option 3 is obtained as:

$$
C_{M}=\sum_{i=1}^{\left\lfloor n_{f, w}+0.5\right\rfloor} C_{i}^{N P V} .
$$

\subsubsection{Buyer cost}

With respect to the fact that performing PM starts after warranty expiration, the expected PM cost imposed on the buyer is obtained by Eq. (30):

$$
C_{P M_{B}}=\sum_{j=n_{P M, w}+1}^{n_{P M, l}} C_{j}^{N P V},
$$

where $n_{P M, l}$ is the number of PM actions performed after the warranty period. Note that in this option, the $\mathrm{PM}$ intervals are calculated in a way that the expected number of failures in each PM interval is equal to the expected number of failures from $t=w$ to the time of the first PM action. Furthermore, $T_{C M_{i}}$ during the post-warranty period should satisfy Eq. (31) as shown in Box III, where $i_{\max }=\max \left[i \mid w<T_{C M_{i}}<l\right]$.

Regarding $n_{f, l}=i_{\max }$, the expected repair cost related to the buyer is as follows:

$$
C_{f_{B}}=\sum_{i=n_{f, w}+1}^{n_{f, l}} C_{i}^{N P V}+C_{s_{B}},
$$

where $C_{s_{B}}$ is the expected failure cost during $\left[T_{C M_{n_{f}, l}}, l\right]$, which is obtained by Eq. (21).

Consequently, the total cost to the buyer can be computed through Eq. (33):

$$
C_{B}=C_{f_{B}}+C_{P M_{B}} .
$$

\section{Optimization approach}

As mentioned in the previous sections, there are three options for PM actions. In each options, a solution approach is considered, which is as follows:

Option 1: As mentioned earlier, in this option, no $\mathrm{PM}$ action is performed during the product lifetime. Therefore, with respect to the fact that decision variables are related to PM actions, there is no optimization model for this option.

Option 2: To earn the buyer and manufacturer satisfaction, simultaneously, a desirability function approach is used. This model utilizes the desirability function presented in [32]. This function transforms a gained solution to a scale-free value $d$ called desirability. Therefore, the desirability values of the manufacturer and the buyer are calculated through Eqs. (34) and (35):

$$
\begin{aligned}
& d\left(C_{M}\right)= \\
& \begin{cases}1 & C_{M}^{\min } \leq C_{M} \\
\frac{C_{M}^{\max }-C_{M}}{C_{M}{ }^{\max }-C_{M}{ }^{\min }} & C_{M}^{\min } \leq C_{M} \leq C_{M}^{\max } \\
0 & C_{M}^{\max } \leq C_{M}\end{cases} \\
& d\left(C_{B}\right)= \\
& \begin{cases}1 & C_{B}^{\min } \leq C_{B} \\
\frac{C_{B}{ }^{\max }-C_{B}}{C_{B}{ }^{\max }-C_{B}{ }^{\min }} & C_{B}^{\min } \leq C_{B} \leq C_{B}^{\max } \\
0 & C_{B}^{\max } \leq C_{B}\end{cases}
\end{aligned}
$$

where $d\left(C_{M}\right)$ and $d\left(C_{B}\right)$ are desirability values of the manufacturer and the buyer. Also, $C_{M}^{\min }$ and $C_{M}^{\max }$ and $C_{B}^{\min }$ and $C_{B}^{\max }$ are the lower and upper boundaries of the manufacturer and buyer costs, respectively.

According to the above-mentioned explanations, the optimization model for Option 2 is obtained as:

$$
\max Z=\min \left(d\left(C_{M}\right), d\left(C_{B}\right)\right) .
$$

Option 3: Since no PM action is implemented in the warranty period, the manufacturer's cost is fixed in

$$
\begin{cases}\int_{w}^{T_{C M_{i}}} r_{0}(t) d t=i & w \leq t<T_{P M_{n_{P M}, w}} \\ \int_{T_{P M_{j}}}^{T_{C M_{i}}} r_{0}\left(v_{j}+t-T_{P M_{j}}\right) d t=i-N \times j & T_{P M_{j}} \leq t<T_{P M_{j+1}}, \quad i=\lfloor N \times j\rfloor+1, \ldots,\lfloor N \times(j+1)\rfloor \\ \int_{T_{P M_{n}} T_{C M, l} r_{0}\left(v_{n_{P M, l}}+t-T_{P M_{n_{P M, l}}}\right) d t} & \\ \quad=i-N \times n_{P M, l} & T_{P M_{n_{P M}, l}} \leq t<l\end{cases}
$$


this option. Accordingly, only the buyer cost should be optimized. With respect to the cost calculated in Eq. (33), the objective function to optimize the buyer's cost is given by:

$\min Z=C_{B}$.

\section{Solution approach}

There are some complexities in the proposed model that make it impractical to achieve the optimum solution using the exact methods. Two of the most crucial complexities are: (1) The objective functions include both continuous and discrete decision variables and (2) some decision variables in the objective functions are within the limits of an integral.

Meta-heuristic algorithms are some of the best methods to gain supreme results in a practical time. There are some papers in the existing literature that have used meta-heuristic algorithms to solve the models similar to the presented model. For instance, Roozitalab and Asgharizadeh [33] applied a Cuckoo algorithm for optimizing the warranty period.

This study utilizes a PSO algorithm for optimizing the proposed mathematical model because of its simplicity in concept, ease of implementation, good performance in optimizing nonlinear problems, computational efficiency, and unique searching mechanism [34]. In recent years, PSO has become one of the most popular meta-heuristic optimization algorithms and has been applied in many researches such as [35-37].

\subsection{Particle Swarm Optimization (PSO) description}

PSO is a population-based swarm intelligence metaheuristic optimization algorithm, which is successfully employed to solve the non-linear and non-convex models with discontinuous space. In this algorithm, a population called particles cooperate to find the optimum values of decision variables in the solution space. Each particle has two characteristics: (1) the fitness value calculated by the objective function and (2) velocity vector that directs the flying of the particle.

In PSO, local and global searches are combined to achieve high search efficiency. The algorithm is initialized by assigning a random position and velocity vectors to each particle. Then, the algorithm searches for the optimal solution by considering the force of inertia and the two "best" values. Between these two values, the first value is called global best (gbest), which is the best solution observed so far, and the other is the personal best (pbest ${ }_{i}$ ) that the $i$ th particle has experienced. In other words, the behavior of a particle is related to the interaction among its personal best, the global best, and its current velocity. In each iteration, the velocity and position of the particle are updated after achieving the two best values.

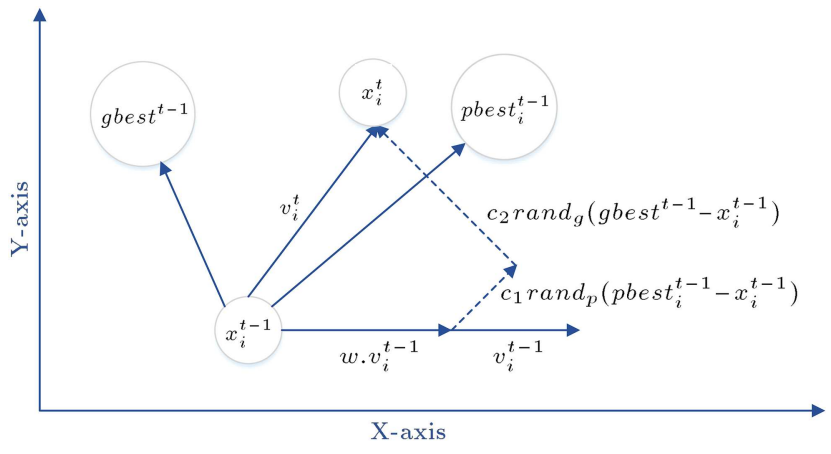

Figure 3. Representation of search point by Particle Swarm Optimization (PSO) algorithm.

Assume $N$ as the number of particles in the swarm. Let $x_{i}^{t}=\left[m, T_{P M_{1}}\right], v_{i}^{t}$, pbest $t_{i}^{t}$ denote the position (the vector of decision variables), velocity, and the personal best of the $i$ th particle in iteration $t$, respectively. The best solution achieved until iteration $t$ is indicated by gbest $t^{t}$ The parameters $c_{1}$ and $c_{2}$ represent the learning and cognition factors, where the value of $\left(c_{1}+c_{2}\right)$ according to [38] is usually considered equal to 4 . Finally, $w$ is the indicator of inertia weight the value of which decreases as the iteration number increases. In other words, the inertia weight in the first iteration has a predetermined value in the interval $[0,1]$. Then, $w$ decreases to $w \times w_{\text {damp }}$ where $w_{\text {damp }}$ is a constant factor less than 1 . Such formulation for $w$ leads to an increase in intensification of the algorithm.

Figure 3 represents a search point by PSO algorithm in a two-dimensional feasible space and Table 3 illustrates the computational procedure of the PSO algorithm in summary.

\subsection{Application of PSO to solving the proposed model}

An important factor in developing a PSO algorithm is solution representation, which could be a series of both real and integer numbers. The solution representation for the proposed model includes two-dimensional particles each of which corresponds to a particular decision variable. In the proposed model, the PM level $(m)$ is an integer while the time of the first PM activity $\left(T_{P M_{1}}\right)$ is a real number.

A uniformly distributed random value is generated to produce the initial value for the continuous decision variable. This random value is between the lower and upper limits of the considered decision variable. Moreover, a random value from a uniform distribution in the interval $[0,1]$ is generated as the initial value of the discrete decision variable. The value of discrete decision variable, i.e. the PM level $(m)$, is acquired according to Eq. (38):

$$
\begin{aligned}
m= & \min \left(\left(m_{\min }+f \operatorname{loor}\left(\left(m_{\max }-m_{\min }+1\right) \times R\right)\right),\right. \\
& \left.m_{\max }\right),
\end{aligned}
$$


Table 3. Complete computational procedure of the Particle Swarm Optimization (PSO) algorithm.

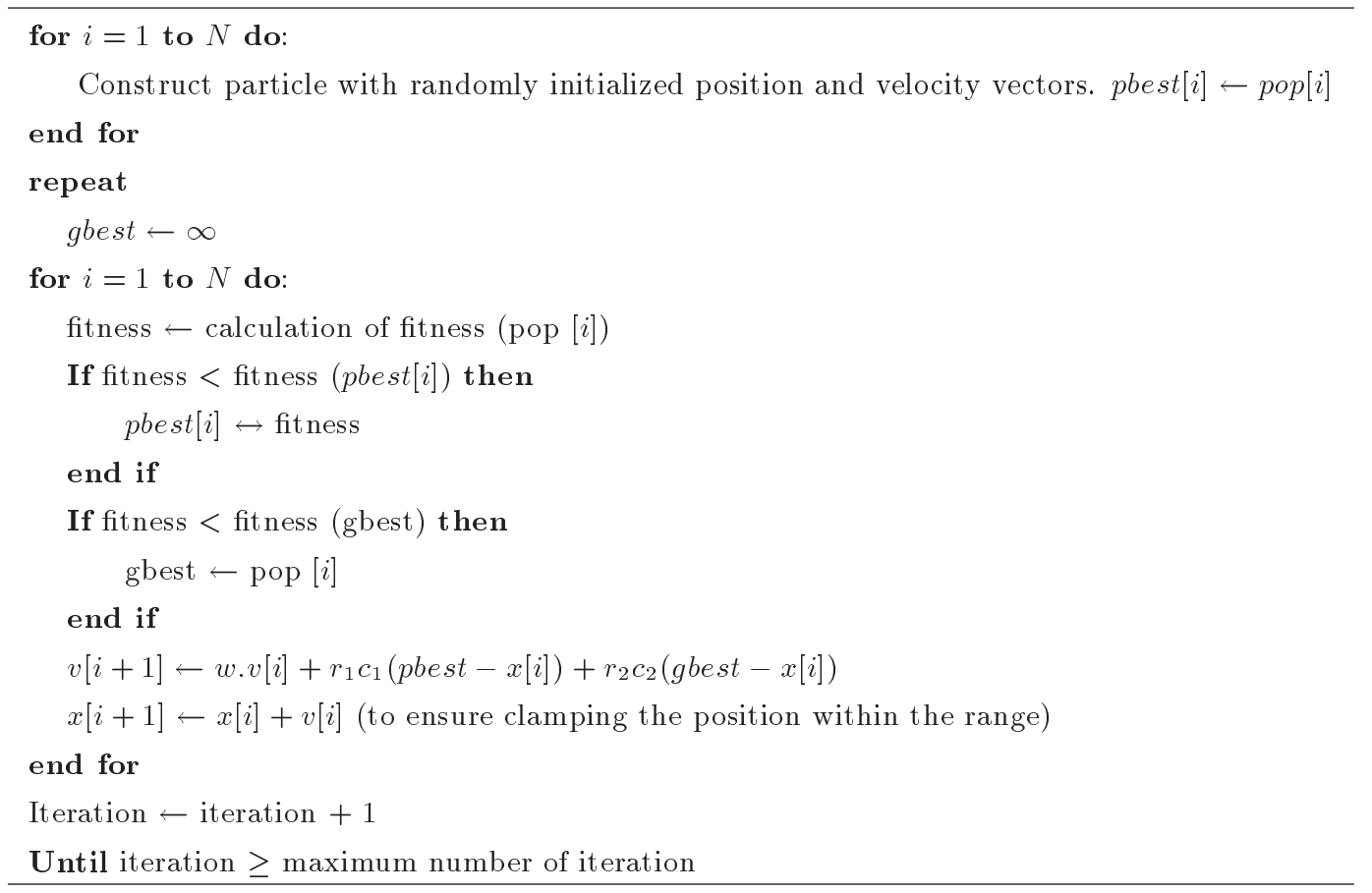

where $m_{\min }$ and $m_{\max }$ are the lower and upper limits of $m$, and $R$ is a uniformly distributed random number with $R \sim U(0,1)$.

\section{Experimental results}

As mentioned earlier, the aim of this study is to find an optimal strategy to minimize the costs imposed on the manufacturer and the buyer by considering the time value of money. In this section, a numerical example is given to demonstrate applicability of the proposed model.

\subsection{Numerical example}

In this section, a numerical example derived from [14] and modified is presented to illustrate applicability of the proposed model. As indicated in Subsection 2.2, the failure rate follows a Weibull distribution with $\beta$ and $\lambda$ parameters. This model assumes that $w=4$, $l=10$ and $C_{f}$ varies from $20 \$$ to $500 \$$ in increments of $40 \$$. The expected costs to the buyer and the manufacturer under each option are calculated with $\alpha=0,0.4,0.1$ and $\beta=2$. Five discrete levels for PM are considered among which the age reduction $\delta(m)$ and the cost corresponding to them are given in Table 4. Also, the specification limits for the expected costs to the buyer and the manufacturer, which are obtained based on the Decision-Maker (DM's experience, are presented in Table 5.

Based on the characteristics and requirements of the proposed model indicated earlier in Section 5, PSO
Table 4. Maintenance level, improvement, and cost (\$).

\begin{tabular}{ccc}
\hline Maintenance level $\boldsymbol{m}$ & $\boldsymbol{\delta}(\mathbf{m})$ & $\boldsymbol{C}_{\boldsymbol{P} \boldsymbol{M}, \boldsymbol{m}}$ \\
\hline 0 & 1.00 & 0 \\
1 & 0.74 & 10 \\
2 & 0.41 & 30 \\
3 & 0.20 & 60 \\
4 & 0.09 & 100 \\
5 & 0.04 & 160 \\
\hline
\end{tabular}

Table 5. Values of desirability function boundaries.

\begin{tabular}{lcccc} 
Parameter & $C_{M \min }$ & $C_{M \max }$ & $C_{B \min }$ & $C_{B \max }$ \\
Value & 50 & 2700 & 100 & 6000 \\
\hline
\end{tabular}

is coded and employed in MATLAB2016 to obtain the optimal solution.

Table 6 represents the expected cost in Option 1 without any PM effort. The optimal values for Option 2 are exhibited in Table 7 . Table 8 includes the optimal values for Option 3 .

According to the results observed in Tables 68, when repair cost $C_{f}$ increases, a higher level of maintenance $\left(m^{*}\right)$ is needed to compensate for the rise in the repair costs imposed on the manufacturer and the buyer. Also, changes in $T_{P M_{1}}^{*}$ show a clear pattern following the changes in $C_{f}$. In other words, with an increase in $C_{f}, T_{P M_{1}}^{*}$ generally decreases, because with higher repair cost, PM actions should be implemented more frequently. 
Table 6. Expected cost under Option $1(\alpha=0,0.04,0.1$ and $\beta=2)$.

\begin{tabular}{|c|c|c|c|c|c|c|c|c|c|}
\hline \multirow[t]{2}{*}{$C_{f}$} & \multicolumn{3}{|c|}{$\alpha=0$} & \multicolumn{3}{|c|}{$\alpha=0.04$} & \multicolumn{3}{|c|}{$\alpha=0.1$} \\
\hline & $C_{M}$ & $C_{B}$ & $d$ & $C_{M}$ & $C_{B}$ & $d$ & $C_{M}$ & $C_{B}$ & $d$ \\
\hline 20 & 80.00 & 420.00 & 0.95 & 70.78 & 310.94 & 0.96 & 59.00 & 199.71 & 0.98 \\
\hline 60 & 240.00 & 1260.00 & 0.80 & 212.33 & 932.83 & 0.86 & 176.99 & 599.12 & 0.92 \\
\hline 100 & 400.00 & 2100.00 & 0.66 & 353.89 & 1554.72 & 0.75 & 294.99 & 998.54 & 0.85 \\
\hline 140 & 560.00 & 2940.00 & 0.52 & 495.45 & 2176.60 & 0.65 & 412.99 & 1397.96 & 0.78 \\
\hline 180 & 720.00 & 3780.00 & 0.38 & 637.00 & 2798.49 & 0.54 & 530.98 & 1797.37 & 0.71 \\
\hline 220 & 880.00 & 4620.00 & 0.23 & 778.56 & 3420.38 & 0.44 & 648.98 & 2196.79 & 0.64 \\
\hline 260 & 1040.00 & 5460.00 & 0.09 & 920.11 & 4042.26 & 0.33 & 766.98 & 2596.21 & 0.58 \\
\hline 300 & 1200.00 & 6300.00 & 0.00 & 1061.67 & 4664.15 & 0.23 & 884.97 & 2995.62 & 0.51 \\
\hline 340 & 1360.00 & 7140.00 & 0.00 & 1203.22 & 5286.04 & 0.12 & 1002.97 & 3395.04 & 0.44 \\
\hline 380 & 1520.00 & 7980.00 & 0.00 & 1344.78 & 5907.92 & 0.02 & 1120.97 & 3794.46 & 0.37 \\
\hline 420 & 1680.00 & 8820.00 & 0.00 & 1486.34 & 6529.81 & 0.00 & 1238.96 & 4193.87 & 0.31 \\
\hline 460 & 1840.00 & 9660.00 & 0.00 & 1627.89 & 7151.70 & 0.00 & 1356.96 & 4593.29 & 0.24 \\
\hline 500 & 2000.00 & 10500.00 & 0.00 & 1769.45 & 7773.58 & 0.00 & 1474.96 & 4992.71 & 0.17 \\
\hline
\end{tabular}

Table 7. Optimal values for Option $2(\alpha=0,0.04,0.1$ and $\beta=2)$.

\begin{tabular}{|c|c|c|c|c|c|c|c|c|c|c|c|c|c|c|c|}
\hline \multirow[t]{2}{*}{$C_{f}$} & \multicolumn{5}{|c|}{$\alpha=0$} & \multicolumn{5}{|c|}{$\alpha=0.04$} & \multicolumn{5}{|c|}{$\alpha=0.1$} \\
\hline & $m^{*}$ & $T_{P M_{1}}^{*}$ & $C_{M}$ & $C_{B}^{*}$ & $d^{*}$ & $m^{*}$ & $T_{P M_{1}}^{*}$ & $C_{M}$ & $C_{B}^{*}$ & $d^{*}$ & $m^{*}$ & $T_{P M_{1}}^{*}$ & $C_{M}$ & $C_{B}^{*}$ & $d^{*}$ \\
\hline 20 & 2 & 3.29 & 136.07 & 299.98 & 0.97 & 2 & 2.94 & 117.71 & 238.88 & 0.97 & 2 & 2.80 & 83.84 & 166.36 & 0.99 \\
\hline 60 & 3 & 2.71 & 275.94 & 610.01 & 0.91 & 3 & 1.96 & 220.46 & 477.61 & 0.94 & 3 & 1.82 & 180.70 & 331.09 & 0.95 \\
\hline 100 & 4 & 1.79 & 377.51 & 860.48 & 0.87 & 3 & 1.96 & 295.77 & 645.44 & 0.91 & 3 & 1.82 & 239.09 & 431.94 & 0.93 \\
\hline 140 & 4 & 1.79 & 448.51 & 1044.67 & 0.84 & 3 & 1.96 & 371.07 & 813.28 & 0.88 & 3 & 1.82 & 297.48 & 532.79 & 0.91 \\
\hline 180 & 4 & 1.79 & 519.52 & 1228.86 & 0.81 & 3 & 1.96 & 446.38 & 981.11 & 0.85 & 3 & 1.82 & 355.87 & 633.63 & 0.88 \\
\hline 220 & 4 & 1.36 & 619.25 & 1401.51 & 0.78 & 4 & 1.47 & 497.13 & 1101.87 & 0.83 & 3 & 1.82 & 414.27 & 734.48 & 0.86 \\
\hline 260 & 4 & 1.36 & 677.29 & 1547.24 & 0.75 & 4 & 1.47 & 554.13 & 1218.57 & 0.81 & 3 & 1.32 & 465.60 & 1020.86 & 0.84 \\
\hline 300 & 4 & 1.36 & 735.34 & 1692.97 & 0.73 & 4 & 1.47 & 611.13 & 1335.28 & 0.79 & 5 & 0.97 & 508.82 & 1085.34 & 0.83 \\
\hline 340 & 5 & 1.42 & 811.76 & 1830.09 & 0.71 & 4 & 1.13 & 657.49 & 1461.21 & 0.77 & 5 & 0.97 & 509.12 & 1145.57 & 0.82 \\
\hline 380 & 5 & 1.42 & 869.62 & 1951.28 & 0.69 & 4 & 1.13 & 702.42 & 1552.59 & 0.75 & 5 & 0.97 & 509.52 & 1205.62 & 0.81 \\
\hline 420 & 5 & 1.42 & 927.47 & 2072.47 & 0.67 & 4 & 1.13 & 747.36 & 1643.98 & 0.74 & 5 & 0.97 & 509.86 & 1265.53 & 0.80 \\
\hline 460 & 5 & 1.42 & 985.33 & 2193.66 & 0.65 & 4 & 1.13 & 792.29 & 1735.36 & 0.72 & 5 & 0.96 & 510.15 & 1325.31 & 0.79 \\
\hline 500 & 5 & 1.08 & 1043.33 & 2228.40 & 0.62 & 4 & 1.13 & 837.22 & 1826.75 & 0.70 & 5 & 0.96 & 510.40 & 1385.01 & 0.78 \\
\hline
\end{tabular}

Table 8. Optimal values for Option $3(\alpha=0,0.02$ and $\beta=2)$.

\begin{tabular}{|c|c|c|c|c|c|c|c|c|c|c|c|c|c|c|c|}
\hline \multirow[t]{2}{*}{$C_{f}$} & \multicolumn{5}{|c|}{$\alpha=0$} & \multicolumn{5}{|c|}{$\alpha=0.04$} & \multicolumn{5}{|c|}{$\alpha=0.1$} \\
\hline & $m^{*}$ & $T_{P M_{1}}^{*}$ & $C_{M}$ & $C_{B}^{*}$ & $d^{*}$ & $m^{*}$ & $T_{P M_{1}}^{*}$ & $C_{M}$ & $C_{B}^{*}$ & $d^{*}$ & $m^{*}$ & $T_{P M_{1}}^{*}$ & $C_{M}$ & $C_{B}^{*}$ & $d^{*}$ \\
\hline 20 & 3 & 6.27 & 80.00 & 292.62 & 0.97 & 3 & 6.27 & 70.78 & 215.31 & 0.98 & 3 & 5.26 & 59.00 & 137.76 & 0.99 \\
\hline 60 & 4 & 5.01 & 240.00 & 609.25 & 0.91 & 4 & 5.01 & 212.33 & 445.36 & 0.94 & 3 & 4.84 & 176.99 & 274.72 & 0.95 \\
\hline 100 & 4 & 4.62 & 400.00 & 833.40 & 0.87 & 4 & 4.62 & 353.89 & 600.72 & 0.89 & 4 & 4.47 & 294.99 & 369.19 & 0.91 \\
\hline 140 & 4 & 4.43 & 560.00 & 1032.18 & 0.81 & 4 & 4.43 & 495.45 & 724.94 & 0.83 & 4 & 4.45 & 412.99 & 434.32 & 0.86 \\
\hline 180 & 4 & 4.43 & 720.00 & 1212.80 & 0.75 & 4 & 4.43 & 637.00 & 844.24 & 0.78 & 4 & 4.43 & 530.98 & 499.04 & 0.82 \\
\hline 220 & 4 & 4.32 & 880.00 & 1381.23 & 0.69 & 4 & 4.43 & 778.56 & 963.53 & 0.73 & 4 & 4.43 & 648.98 & 563.58 & 0.77 \\
\hline 260 & 5 & 4.33 & 1040.00 & 1534.37 & 0.63 & 4 & 4.32 & 920.11 & 1071.76 & 0.67 & 4 & 4.43 & 766.98 & 628.10 & 0.73 \\
\hline 300 & 5 & 4.33 & 1200.00 & 1671.97 & 0.57 & 5 & 4.33 & 1061.67 & 1173.84 & 0.62 & 4 & 4.33 & 884.97 & 690.06 & 0.68 \\
\hline 340 & 5 & 4.24 & 1360.00 & 1790.25 & 0.51 & 5 & 4.24 & 1203.22 & 1259.89 & 0.56 & 4 & 4.32 & 1002.97 & 747.66 & 0.64 \\
\hline 380 & 5 & 4.24 & 1520.00 & 1906.75 & 0.45 & 5 & 4.24 & 1344.78 & 1335.73 & 0.51 & 5 & 4.24 & 1120.97 & 797.38 & 0.60 \\
\hline 420 & 5 & 4.24 & 1680.00 & 2023.25 & 0.38 & 5 & 4.24 & 1486.34 & 1411.56 & 0.46 & 5 & 4.24 & 1238.96 & 837.45 & 0.55 \\
\hline 460 & 5 & 4.18 & 1840.00 & 2137.00 & 0.32 & 5 & 4.24 & 1627.89 & 1487.40 & 0.40 & 5 & 4.24 & 1356.96 & 877.52 & 0.51 \\
\hline 500 & 5 & 4.18 & 2000.00 & 2239.34 & 0.26 & 5 & 4.24 & 1769.45 & 1563.24 & 0.35 & 5 & 4.24 & 1474.96 & 917.60 & 0.46 \\
\hline
\end{tabular}


Table 9. Optimal Preventive Maintenance (PM) strategy $(\beta=2)$.

\begin{tabular}{|c|c|c|c|c|c|c|c|c|c|}
\hline \multirow{3}{*}{$C_{f}$} & \multicolumn{3}{|c|}{$\alpha=0$} & \multicolumn{3}{|c|}{$\alpha=0.04$} & \multicolumn{3}{|c|}{$\alpha=0.1$} \\
\hline & Option 1 & Option 2 & Option 3 & Option 1 & Option 2 & Option 3 & Option 1 & Option 2 & Option 3 \\
\hline & $d$ & $d^{*}$ & $d^{*}$ & $d$ & $d^{*}$ & $d^{*}$ & $d$ & $d^{*}$ & $d^{*}$ \\
\hline 20 & 0.95 & 0.97 & 0.97 & 0.96 & 0.97 & 0.98 & 0.98 & 0.99 & 0.99 \\
\hline 60 & 0.80 & 0.91 & 0.91 & 0.86 & 0.94 & 0.94 & 0.92 & 0.95 & 0.95 \\
\hline 100 & 0.66 & 0.87 & 0.87 & 0.75 & 0.91 & 0.89 & 0.85 & 0.93 & 0.91 \\
\hline 140 & 0.52 & 0.84 & 0.81 & 0.65 & 0.88 & 0.83 & 0.78 & 0.91 & 0.86 \\
\hline 180 & 0.38 & 0.81 & 0.75 & 0.54 & 0.85 & 0.78 & 0.71 & 0.88 & 0.82 \\
\hline 220 & 0.23 & 0.78 & 0.69 & 0.44 & 0.83 & 0.73 & 0.64 & 0.86 & 0.77 \\
\hline 260 & 0.09 & 0.75 & 0.63 & 0.33 & 0.81 & 0.67 & 0.58 & 0.84 & 0.73 \\
\hline 300 & 0.00 & 0.73 & 0.57 & 0.23 & 0.79 & 0.62 & 0.51 & 0.83 & 0.68 \\
\hline 340 & 0.00 & 0.71 & 0.51 & 0.12 & 0.77 & 0.56 & 0.44 & 0.82 & 0.64 \\
\hline 380 & 0.00 & 0.69 & 0.45 & 0.02 & 0.75 & 0.51 & 0.37 & 0.81 & 0.60 \\
\hline 420 & 0.00 & 0.67 & 0.38 & 0.00 & 0.74 & 0.46 & 0.31 & 0.80 & 0.55 \\
\hline 460 & 0.00 & 0.65 & 0.32 & 0.00 & 0.72 & 0.40 & 0.24 & 0.79 & 0.51 \\
\hline 500 & 0.00 & 0.62 & 0.26 & 0.00 & 0.70 & 0.35 & 0.17 & 0.78 & 0.46 \\
\hline
\end{tabular}

We consider that time value of money not only reduces the cost, but also increases the desirability value. As it can be seen in Tables 6-8, under a fixed $C_{f}$ in each option, the manufacturer and the buyer's costs, when $\alpha=0.04$, and 0.1 , are less than $\alpha=0$. When $\alpha$ is 0.04 , the cost reduction is between $\% 26$ and $\% 30$, while when $\alpha$ is considered equal to 0.1 , these values increase to $\% 35$ and $\% 59$, respectively. The reduction in cost, which is estimated to reach \%59, confirms the fact that taking the time value of money into consideration has a significant effect on the warranty cost estimation. It is also obvious that at higher interest rates, the impact is more severe. Therefore, it can be concluded that in countries with higher interest rates, considering interest rate in evaluations has a significant impact on economic forecasts and the related decisions.

On the other hand, in some cases (Options 2 and 3), it also affects the decision variable values, significantly. According to Tables 7 and 8, for most values of $C_{f}$, the decision variables, i.e. $m^{*}$ and $T_{P M_{1}}^{*}$, decrease when $\alpha$ increases. This supports the claim that a greater number of lower-level PM actions are required in these situations.

Table 9 represents a comparison between different options with $\beta=2$. As it can be seen, in cases of $\alpha=$ $0,0.04,0.1$, when $C_{f}$ is low $\left(C_{f} \leq \$ 60\right)$, the optimal PM strategy is Option 3 (performing PM after warranty expiration). That is, when the cost of repair is very low, the manufacturer prefers to conduct no PM actions. By increasing $C_{f}\left(C_{f} \geq 100\right)$, the optimal strategy switches to Option 2 (performing PM during the life cycle).

\subsection{Comparative study}

6.2.1. Periodic and non-periodic

In this sub-section, a comparative study is conducted between the presented model and a periodic PM warranty model with $\tau=0.33$ (the fixed pre-specified PM interval that is considered by Kim et al. 2004) [14]), $w=4$, and $l=10$ to validate effectiveness of the presented model. The optimal strategies under both the periodic and the non-periodic PM warranties by considering the time value of money are compared in Table 10.

\subsubsection{Single- and multi-objective modes}

In the following, a comparative study is carried out between the bi-objective mode and the single-objective modes. The manufacturer and the buyer's costs are considered in accordance with the values in Table 5 and the rest of the parameters are considered in accordance with the previous example. Table 11 presents the results for the single-objective and bi-objective optimization modes. In the single-objective mode, only minimizing the manufacturer's cost is considered and in the bi-objective mode, the goal is to minimize the costs to the manufacturer and the buyer by maximizing the minimum utility (manufacturer and buyer).

The results of Table 11 show that the buyer's costs decrease from $25 \%$ to $42 \%$ in the bi-objective optimization compared to the single-objective optimization in different numerical examples. As a result, the buyer's desirability increases, indicating the effect of considering the buyer's interest in the objective function. Furthermore, the manufacturer's cost in the bi-objective mode increases compared to that in the 
Table 10. Optimal cost and desirability of periodic and non-periodic Preventive Maintenance (PM) warranty models.

\begin{tabular}{cccccccc}
\hline $\boldsymbol{C}_{\boldsymbol{f}}$ & \multicolumn{3}{c}{ Periodic } & PM warranty & & \multicolumn{3}{c}{ Non-periodic PM warranty } \\
\cline { 2 - 3 } & $\boldsymbol{C}_{\boldsymbol{M}}^{*}$ & $\boldsymbol{C}_{\boldsymbol{B}}^{*}$ & $\boldsymbol{d}^{*}$ & & $\boldsymbol{C}_{\boldsymbol{M}}^{*}$ & $\boldsymbol{C}_{\boldsymbol{B}}^{*}$ & $\boldsymbol{d}^{*}$ \\
\hline 20 & 80.00 & 420.00 & 0.95 & & 75.23 & 250.71 & 0.97 \\
60 & 240.00 & 1092.59 & 0.83 & & 225.71 & 520.14 & 0.93 \\
100 & 400.00 & 1460.98 & 0.77 & & 313.36 & 748.29 & 0.89 \\
140 & 560.00 & 1794.54 & 0.71 & & 426.12 & 905.27 & 0.85 \\
180 & 720.00 & 1998.69 & 0.68 & & 493.61 & 1064.37 & 0.83 \\
220 & 952.88 & 2103.22 & 0.66 & & 532.88 & 1234.87 & 0.80 \\
260 & 995.22 & 2289.25 & 0.63 & & 616.88 & 1376.80 & 0.78 \\
300 & 1037.57 & 2475.29 & 0.60 & & 667.80 & 1494.99 & 0.76 \\
340 & 1079.91 & 2661.33 & 0.57 & & 718.71 & 1613.15 & 0.74 \\
380 & 1122.25 & 2847.37 & 0.53 & & 769.83 & 1731.52 & 0.72 \\
420 & 1164.59 & 3033.41 & 0.50 & & 820.51 & 1849.48 & 0.70 \\
460 & 1206.93 & 3219.45 & 0.47 & & 871.46 & 1967.70 & 0.68 \\
500 & 1531.72 & 3320.67 & 0.44 & & 938.14 & 2059.14 & 0.66 \\
\hline
\end{tabular}

Table 11. Optimal cost and desirability in single- and bi-objective modes.

\begin{tabular}{|c|c|c|c|c|c|c|c|c|c|c|}
\hline \multirow[t]{2}{*}{$C_{f}$} & \multicolumn{5}{|c|}{ Single-objective } & \multicolumn{5}{|c|}{ Bi-objective } \\
\hline & $m^{*}$ & $T_{P M_{1}}^{*}$ & $C_{M}^{*}$ & $C_{B}^{*}$ & $d^{*}$ & $m^{*}$ & $T_{P M_{1}}^{*}$ & $C_{M}^{*}$ & $C_{B}^{*}$ & $d^{*}$ \\
\hline 20 & 1 & 1.81 & 89.96 & 445.44 & 0.94 & 2 & 3.28 & 128.54 & 258.76 & 0.97 \\
\hline 60 & 2 & 1.82 & 196.96 & 777.65 & 0.89 & 3 & 1.96 & 233.44 & 553.05 & 0.92 \\
\hline 100 & 2 & 1.82 & 290.16 & 1105.14 & 0.83 & 3 & 1.96 & 313.36 & 748.29 & 0.89 \\
\hline 140 & 3 & 1.59 & 365.94 & 1193.18 & 0.81 & 4 & 1.79 & 426.12 & 905.27 & 0.85 \\
\hline 180 & 3 & 1.59 & 437.70 & 1400.47 & 0.78 & 4 & 1.79 & 493.61 & 1064.37 & 0.83 \\
\hline 220 & 3 & 1.59 & 509.47 & 1607.76 & 0.74 & 4 & 1.61 & 532.88 & 1234.87 & 0.80 \\
\hline 260 & 4 & 0.85 & 477.81 & 2006.61 & 0.68 & 4 & 1.27 & 616.88 & 1376.80 & 0.78 \\
\hline 300 & 4 & 0.85 & 477.81 & 2128.64 & 0.66 & 4 & 1.27 & 667.80 & 1494.99 & 0.76 \\
\hline 340 & 4 & 0.85 & 477.81 & 2250.68 & 0.64 & 4 & 1.27 & 718.71 & 1613.15 & 0.74 \\
\hline 380 & 4 & 0.85 & 477.81 & 2372.71 & 0.61 & 4 & 1.27 & 769.83 & 1731.52 & 0.72 \\
\hline 420 & 4 & 0.85 & 477.81 & 2494.74 & 0.59 & 4 & 1.27 & 820.51 & 1849.48 & 0.70 \\
\hline 460 & 4 & 0.85 & 477.81 & 2616.78 & 0.57 & 4 & 1.27 & 871.46 & 1967.70 & 0.68 \\
\hline 500 & 4 & 0.85 & 477.81 & 2738.81 & 0.55 & 4 & 1.06 & 938.14 & 2059.14 & 0.66 \\
\hline
\end{tabular}

single-objective mode, which is the cost the manufacturer has to pay to obtain the buyer's satisfaction and reduce their costs. However, in general, the costs incurred by both sides (the total costs to the buyer and the manufacturer) improve by $6 \%$ to $27 \%$. PM action in the single-objective mode begins at a faster rate than in the bi-objective mode at all costs of repair, which is due to the reduction in the number of expected failures during the warranty period, and reduces the costs imposed on the manufacturer.

\subsection{Sensitivity analysis}

In the previous section, the effect of parameters $C_{f}$ and $\alpha$ were investigated on the optimal solutions. In
Table 12. Parameters of sensitivity analysis.

\begin{tabular}{lcccc}
\hline Parameter & $\lambda$ & $\beta$ & $\alpha$ & $l$ \\
Value & 0.25 & 2 & 0.04 & 10 \\
\hline
\end{tabular}

this section, a sensitivity analysis is conducted over warranty period $w$ and lifecycle $l$ while the other parameters are set to their nominal values (see Table 12).

\subsubsection{Varying $w$}

Table 13 shows the optimal option and desirability value under $w=3,4,5$ when $C_{f}$ varies from 20 to 500 . Also, the optimal desirability value is graphically pre- 
Table 13. Optimal option and desirability under $w=3,4,5$.

\begin{tabular}{|c|c|c|c|c|c|c|}
\hline \multirow[t]{2}{*}{$C_{f}$} & \multicolumn{2}{|l|}{$w=3$} & \multicolumn{2}{|l|}{$w=4$} & \multicolumn{2}{|l|}{$w=5$} \\
\hline & Optimal option & $d^{*}$ & Optimal option & $d^{*}$ & Optimal option & $d^{*}$ \\
\hline 20 & 2 & 0.97 & 3 & 0.97 & 3 & 0.97 \\
\hline 60 & 2 & 0.93 & 3 & 0.93 & 2 & 0.91 \\
\hline 100 & 2 & 0.89 & 2 & 0.89 & 2 & 0.87 \\
\hline 140 & 2 & 0.85 & 2 & 0.86 & 2 & 0.83 \\
\hline 180 & 2 & 0.83 & 2 & 0.83 & 2 & 0.79 \\
\hline 220 & 2 & 0.80 & 2 & 0.81 & 2 & 0.76 \\
\hline 260 & 2 & 0.78 & 2 & 0.78 & 2 & 0.73 \\
\hline 300 & 2 & 0.77 & 2 & 0.76 & 2 & 0.70 \\
\hline 340 & 2 & 0.75 & 2 & 0.74 & 2 & 0.67 \\
\hline 380 & 2 & 0.73 & 2 & 0.72 & 2 & 0.65 \\
\hline 420 & 2 & 0.71 & 2 & 0.70 & 2 & 0.62 \\
\hline 460 & 2 & 0.70 & 2 & 0.68 & 2 & 0.60 \\
\hline 500 & 2 & 0.68 & 2 & 0.66 & 2 & 0.57 \\
\hline
\end{tabular}

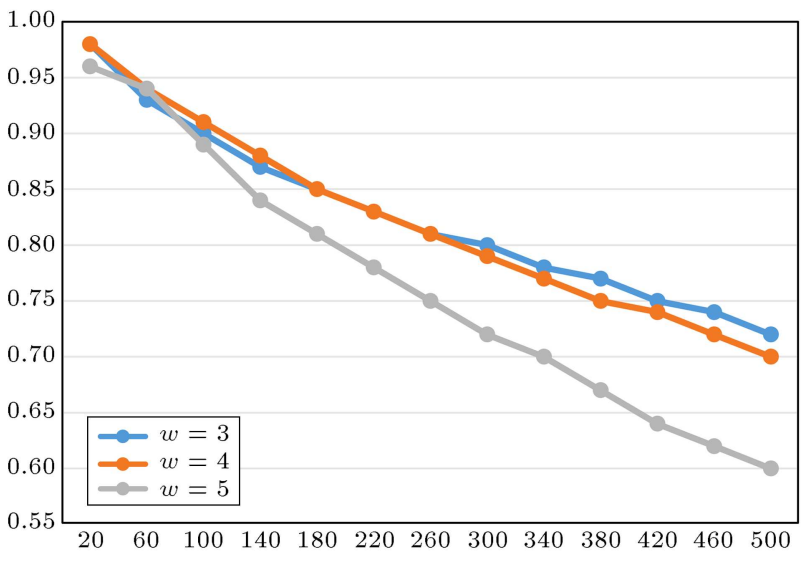

Figure 4. The effect of $w$ on $d^{*}$.

sented in Figure 4. As it can be seen, for different values of repair cost, $w=5$ has the lowest desirability value. Moreover, at low repair costs $\left(C_{f} \leq 260\right), w=4$ and at high repair costs $\left(C_{f} \geq 300\right), w=3$ have the highest desirability values. Therefore, it can be said that when the repair cost is low, since the expected repair cost imposed on the manufacturer can be maintained at an acceptable level by employing PM actions, the manufacturer can provide a longer warranty. On the other hand, as repair cost increases, the manufacturer is forced to decrease the length of warranty period. In other words, the manufacturer should offer a shorter warranty. Furthermore, the obtained results indicate that implementing PM actions in the total life cycle is the optimal option in most instances, except for the ones in which repair cost is very low.

\subsubsection{Varying $l$}

Table 14 presents the optimal decision variables under different life cycles and repair cost values. As can

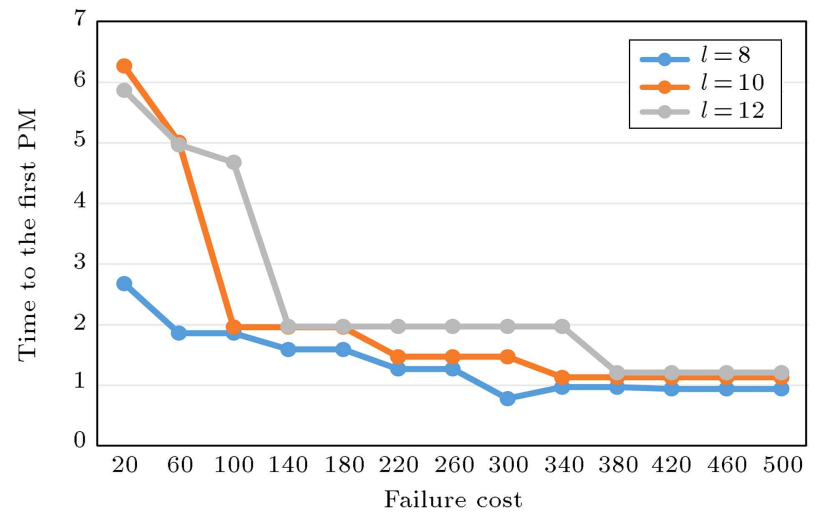

Figure 5. The effect of $l$ on $T_{P M_{1}}$.

be seen in Figure 5, an increase in the life cycle usually leads to higher $T_{P M_{1}}$, while the higher is the repair cost, the lower is $T_{P M_{1}}$. Furthermore, the obtained results indicate that in most of the considered instances, Option 2 has better performance than the other ones in increasing the desirability values of both the manufacturer and the buyer. Also, an increase in the life cycle, as expected, raises the number of product failures in the post-warranty period. Consequently, the expected cost imposed on the buyer extremely increases and the desirability value decreases. As expected, the results confirm the fact that as life cycle increases, the optimal maintenance level usually follows a nondecreasing trend.

\section{Conclusions}

On the one hand, high costs of repair and maintenance in the post-warranty period have a severely negative impact on buyer satisfaction level and on the other 
Table 14. Optimal solution and desirability under $l=8,10,12$.

\begin{tabular}{|c|c|c|c|c|c|c|c|c|c|c|c|c|}
\hline \multirow[t]{2}{*}{$C_{f}$} & \multicolumn{4}{|c|}{$l=8$} & \multicolumn{4}{|c|}{$l=10$} & \multicolumn{4}{|c|}{$l=12$} \\
\hline & $\begin{array}{c}\text { Optimal } \\
\text { option }\end{array}$ & $m^{*}$ & $T_{P M_{1}}^{*}$ & $d^{*}$ & $\begin{array}{c}\text { Optimal } \\
\text { option }\end{array}$ & $m^{*}$ & $T_{P M_{1}}^{*}$ & $d^{*}$ & $\begin{array}{c}\text { Optimal } \\
\text { option }\end{array}$ & $m^{*}$ & $T_{P M_{1}}^{*}$ & $d^{*}$ \\
\hline 20 & 2 & 1 & 2.68 & 0.98 & 3 & 3 & 6.27 & 0.98 & 3 & 3 & 5.87 & 0.97 \\
\hline 60 & 2 & 2 & 1.86 & 0.95 & 3 & 4 & 5.01 & 0.94 & 3 & 4 & 4.97 & 0.92 \\
\hline 100 & 2 & 2 & 1.86 & 0.91 & 2 & 3 & 1.96 & 0.91 & 3 & 4 & 4.68 & 0.89 \\
\hline 140 & 2 & 3 & 1.59 & 0.89 & 2 & 3 & 1.96 & 0.88 & 2 & 4 & 1.97 & 0.86 \\
\hline 180 & 2 & 3 & 1.59 & 0.86 & 2 & 3 & 1.96 & 0.85 & 2 & 4 & 1.97 & 0.83 \\
\hline 220 & 2 & 3 & 1.27 & 0.84 & 2 & 4 & 1.47 & 0.83 & 2 & 4 & 1.97 & 0.80 \\
\hline 260 & 2 & 3 & 1.27 & 0.81 & 2 & 4 & 1.47 & 0.81 & 2 & 4 & 1.97 & 0.78 \\
\hline 300 & 2 & 4 & 0.78 & 0.80 & 2 & 4 & 1.47 & 0.79 & 2 & 4 & 1.97 & 0.75 \\
\hline 340 & 2 & 5 & 0.97 & 0.80 & 2 & 4 & 1.13 & 0.77 & 2 & 4 & 1.97 & 0.72 \\
\hline 380 & 2 & 5 & 0.97 & 0.80 & 2 & 4 & 1.13 & 0.75 & 2 & 5 & 1.21 & 0.70 \\
\hline 420 & 2 & 5 & 0.94 & 0.79 & 2 & 4 & 1.13 & 0.74 & 2 & 5 & 1.21 & 0.69 \\
\hline 460 & 2 & 5 & 0.94 & 0.78 & 2 & 4 & 1.13 & 0.72 & 2 & 5 & 1.21 & 0.67 \\
\hline 500 & 2 & 5 & 0.94 & 0.77 & 2 & 4 & 1.13 & 0.70 & 2 & 5 & 1.21 & 0.66 \\
\hline
\end{tabular}

hand, dissatisfaction results in the loss of potential buyers through the negative word-of-mouth effect as well as switching of the existing buyers to the competitors. Therefore, this study aimed to maximize both the manufacture and the buyer's satisfaction, simultaneously. In this regard, a non-periodic Preventive Maintenance $(\mathrm{PM})$ strategy was presented in which PM actions were carried out at discrete time instants such that the expected number of failures remained constant over all PM intervals. To confirm superiority of the presented non-periodic model, a comparative study was conducted on the periodic and non-periodic PM strategies. The obtained results indicated that the proposed model not only provided higher desirability, but also imposed lower costs on both the buyer and the manufacturer.

To fill the gap between the simplified assumptions in the existing models and the real production conditions, this study considered two other important issues: (1) time value of money and (2) the calendar time of the first PM action as decision variables. Since the warranty period and product lifetime are often more than six months, according to the obtained results, considering the time value of money has a considerable impact on more accurate estimation of the cost.

To make further improvements, several types of failures could be considered each of which affects the occurrence rates of the others. Furthermore, it is a reasonable assumption that the cost of minimal repair may increase with the age of the item. Thus, it is worthwhile to consider the cost of minimal repair as a function of the product age. Also, this problem could be considered under other types of warranty policies like pro-rata.

\section{References}

1. Chen, C.-K., Lo, C.-C., and Weng, T.-C. "Optimal production run length and warranty period for an imperfect production system under selling price dependent on warranty period", Eur. J. Oper. Res., 259(2), pp. 401-412 (2017).

2. Tian, Z., Jia Y., Li, X., Van Doan, C., and Revhaug, I. "Modelling upgrading maintenance policy in the onedimensional renewing warranty period", J. Shanghai Jiaotong Univ., 21(6), pp. 737-743 (2016).

3. Taleizadeh, A.A., Khaligh, P.P., and Moon, I. "Hybrid NSGA-II for an imperfect production system considering product quality and returns under two warranty policies", Appl. Soft Comput., 75, pp. 333-348 (2019).

4. Mahmoudi, A. and Shavandi, H. "Analyzing price, warranty length, and service capacity under a fuzzy environment: Genetic algorithm and fuzzy system", Sci. Iran., 20(3), pp. 975-982 (2013).

5. Murthy, D.N.P. and Djamaludin, I. "New product warranty: A literature review", Int. J. Prod. Econ., 79(3), pp. 231-260 (2002).

6. Darghouth, M.N., Chelbi, A., and Ait-kadi, D. "Investigating reliability improvement of second-hand production equipment considering warranty and preventive maintenance strategies", Int. J. Prod. Res., 55(16), pp. 4643-4661 (2017).

7. Faridimehr, S. and Niaki, S.T.A. "Optimal strategies for price, warranty length, and production rate of a new product with learning production cost", Sci. Iran., Trans. E, Ind. Eng., 20(6), pp. 2247-2258 (2013).

8. Darghouth, M.N., Aït-Kadi, D., and Chelbi, A. "Joint optimization of design, warranty and price for products sold with maintenance service contracts", Reliab. Eng. Syst. Saf., 165, pp. 197-208 (2017). 
9. Marshall, S., Arnold, R., Chukova, S., et al. "Warranty cost analysis: Increasing warranty repair times", Appl. Stoch. Model. Bus. Ind., 34(4), pp. 544-561 (2018).

10. Wang, X. and Su, C. "A two-dimensional preventive maintenance strategy for items sold with warranty", Int. J. Prod. Res., 54(19), pp. 5901-5915 (2016).

11. Murthy, D.N.P., Solem, O., and Roren, T. "Product warranty logistics: Issues and challenges", Eur. J. Oper. Res., 156(1), pp. 110-126 (2004).

12. Murthy, D.N.P. "Product warranty and reliability", Ann. Oper. Res., 143(1), pp. 133-146 (2006).

13. Djamaludin, I., Murthy, D.N.P., and Kim, C.S. "Warranty and preventive maintenance", Int. J. Reliab. Qual. Saf. Eng., 8(02), pp. 89-107 (2001).

14. Kim, C.S. Djamaludin, I., and Murthy, D.N.P. "Warranty and discrete preventive maintenance", Reliab. Eng. Syst. Saf., 84(3), pp. 301-309 (2004).

15. Shafiee, M. and Chukova, S. "Maintenance models in warranty: A literature review", Eur. J. Oper. Res., 229(3), pp. 561-572 (2013).

16. Wang, X. and Xie, W. "Two-dimensional warranty: A literature review", Proc. Inst. Mech. Eng. Part $O J$. Risk Reliab., p. 1748006X17742776 (2017).

17. Wu, J., Xie, M., and Ng, T.S.A. "On a general periodic preventive maintenance policy incorporating warranty contracts and system ageing losses", Int. J. Prod. Econ., 129(1), pp. 102-110 (2011).

18. Park, M., Jung, K.M., and Park, D.H. "Optimal maintenance strategy under renewable warranty with repair time threshold", Appl. Math. Model., 43, pp. 498-508 (2017).

19. Su, C. and Wang, X. "Optimizing upgrade level and preventive maintenance policy for second-hand products sold with warranty", Proc. Inst. Mech. Eng. Part O J. Risk Reliab., 228(5), pp. 518-528 (2014).

20. Huang, Y.-S., Huang, C.-D., and Ho, J.-W. "A customized two-dimensional extended warranty with preventive maintenance", Eur. J. Oper. Res., 257(3), pp. 971-978 (2017).

21. Park, M. and Pham, H. "Cost models for age replacement policies and block replacement policies under warranty", Appl. Math. Model., 40(9), pp. 5689-5702 (2016).

22. Bouguerra, S., Chelbi, A., and Rezg, N. "A decision model for adopting an extended warranty under different maintenance policies", Int. J. Prod. Econ., 135(2), pp. 840-849 (2012).

23. Salmasnia, A. and Yazdekhasti, A. "A bi-objective model to optimize periodic preventive maintenance strategy during warranty period by considering customer satisfaction", Int. J. Syst. Assur. Eng. Manag., 8(4), pp. 770-781 (2017).

24. Teng, H.-M. "Extended warranty pricing considering the time of money", J. Inf. Optim. Sci., 27(2), pp. 401-409 (2006).
25. Fang, C.-C. and Huang, Y.-S. "A study on decisions of warranty, pricing, and production with insufficient information", Comput. Ind. Eng., 59(2), pp. 241-250 (2010).

26. Shahanaghi, K., Noorossana, R., Jalali-Naini, S.G., and Heydari, M. "Failure modeling and optimizing preventive maintenance strategy during two-dimensional extended warranty contracts", Eng. Fail. Anal., 28, pp. 90-102 (2013).

27. Ambad, P.M. and Kulkarni, M.S. "A methodology for design for warranty with focus on reliability and warranty policies", J. Adv. Manag. Res., 10(1), pp. 139-155 (2013).

28. Su, C. and Wang, X. "A study of availability-based warranty policy", in Industrial Engineering and Engineering Management (IEEM), 2016 IEEE International Conference on, pp. 1655-1659 (2016).

29. Moeini, A., Foumani, M., and Jenab, K. "Utilisation of pruned Pareto-optimal solutions in the multi objective optimisation: an application to system redundancy allocation problems", Int. J. Appl. Decis. Sci., 6(1), pp. 50-65 (2013).

30. Moeini, A., Jenab, K., Mohammadi, M., and Foumani, M. "Fitting the three-parameter Weibull distribution with cross entropy", Appl. Math. Model., 37(9), pp. 6354-6363 (2013).

31. Kijima, M. "Some results for repairable systems with general repair", J. Appl. Probab., 26(01), pp. 89-102 (1989).

32. Salmasnia, A., Bashiri, M., and Salehi, M. "A robust interactive approach to optimize correlated multiple responses", Int. J. Adv. Manuf. Technol., 67(5-8), pp. 1923-1935 (2013).

33. Roozitalab, A. and Asgharizadeh, E. "Optimizing the warranty period by cuckoo meta-heuristic algorithm in heterogeneous customers' population", J. Ind. Eng. Int., 9(1), pp. 1-6 (2013).

34. Talbi, E.-G., Metaheuristics: From Design to Implementation, 74, John Wiley \& Sons (2009).

35. Mahmoodian, V., Jabbarzadeh, A., and Rezazadeh, H. "A novel intelligent particle swarm optimization algorithm for solving cell formation problem", Neural Comput. Appl., 31(2), pp. 801-815 (2017).

36. Bui, K.-T.T., Bui, D.T., Zou, J., et al. "A novel hybrid artificial intelligent approach based on neural fuzzy inference model and particle swarm optimization for horizontal displacement modeling of hydropower dam", Neural Comput. Appl., 29(12), pp. 1495-1506 (2016).

37. Salmasnia, A., Abdzadeh, B., and Namdar, M. "A joint design of production run length, maintenance policy and control chart with multiple assignable causes", J. Manuf. Syst., 42, pp. 44-56 (2017).

38. Kennedy, J. "Particle swarm optimization", in Encyclopedia of Machine Learning, Springer, pp. 760-766 (2011). 


\section{Biographies}

Ali Salmasnia is currently an Associate Professor at University of Qom, Qom, Iran. His research interests include quality engineering, reliability, applied multivariate statistics, and multi-criteria decision making. He is the author or co-author of various papers published in Computers \& Industrial Engineering, Journal of Manufacturing Systems, Applied Soft Computing, Neurocomputing, Applied Mathematical Modelling, Expert Systems with Applications, IEEE Transactions on Engineering Management, International Journal of Information Technology and Decision Making, TOP, Quality and Reliability Engineering International, Communications in Statistics-Simulation and Computation, International Journal of Advanced Manufacturing Technology, and Scientia Iranica.

Ali Shahidian is an MSc student in the Department of Industrial Engineering, Faculty of Technology and Engineering, University of Qom. His current research interests include maintenance, warranty, and multicriteria decision making.

Mesbah Seivandian is an MSc student in the Department of Industrial Management, Faculty of Management, University of Tehran. He received his BSc degree from the University of Qom in Qom, Iran. His current research interests include mathematical modeling, machine learning, data mining, and multicriteria decision making.

Behnam Abdzadeh is currently a $\mathrm{PhD}$ candidate in the Faculty of Industrial Engineering, Iran University of Science and Technology. His research interests include quality engineering, reliability, project management and transportation. $\mathrm{He}$ is the author or co-author of various papers published in the Journal of Manufacturing Systems, Neural Computing and Applications, Communications in Statistics-Simulation and Computation, Journal of Industrial and System Engineering, and Scientia Iranica. 